\title{
Experimental Modeling of the Effect of Terrain Slope on Marginal Burning
}

\author{
XIANGYANG ZHOU ${ }^{1}$, SHANKAR MAHALINGAM ${ }^{1}$, and DAVID WEISE ${ }^{2}$ \\ ${ }^{1}$ Department of Mechanical Engineering \\ University of California \\ Riverside, CA 92521, USA \\ ${ }^{2}$ Forest Fire Laboratory, Pacific Southwest Research Station \\ USDA Forest Service \\ Riverside, CA 92507, USA
}

\begin{abstract}
A series of laboratory fire spread experiments were completed to analyze the effect of terrain slope on marginal burning behavior of live chaparral shrub fuels that grow in the mountains of southern California. We attempted to burn single species fuel beds of four common chaparral plants under various fuel bed configurations and ambient conditions. Seventy-three (or $42 \%$ ) of the 173 fires successfully propagated the $2.0 \mathrm{~m}$ length of the elevated fuel bed for slope percent ranging from $-70 \%$ to $70 \%$. There exists a critical slope above which fire spread is successful, and below which fire spread is unsuccessful. Critical slope varied widely with fuel type, moisture content, and fuel loading. Upslope and downslope orientations affected marginal burning behavior differently. In examining a special fuel bed slope set-up, it was found the upslope fire spread depended not only on the increased radiant heat transfer but also on the aerodynamic effect created by the interaction of the flame with the inclined surface. Under certain conditions, the convective heat induced by this interaction became the dominant mechanism determining fire spread success. A stepwise logistic regression model was developed from the data to predict the probability of successful fire spread. It is expected that this model may be helpful in providing guidelines for prescribed fire application.
\end{abstract}

KEYWORDS: slope, marginal burning, chaparral, prescribed fire, flame spread

\section{INTRODUCTION}

Land management agencies in California of the United States use prescribed fire to burn fire-prone brush land to reduce wildland fuels and prevent wildfires [1]. Because of the risk of damage due to fire, prescribed fire is often carried out under marginal burning conditions by selecting proper conditions for wind, temperature, relative humidity, landscape, and fuel moisture content. Marginal burning is a situation in which the fire either spreads, usually a desired outcome, or fails to spread after ignition. The marginal burning conditions often result in low-intensity fires that can be successfully controlled and that produce a desired mosaic of burned and unburned vegetation. In California, several tools are used by fire managers to aid in the use of prescribed fire in chaparral [25]. Despite the availability of these tools, our ability to predict fire behavior in live chaparral fuels is still limited by two factors: 1) current fire spread models were designed primarily for dead, not living, fuels and 2) only a limited set of experimental data on marginal burning in live fuels exists, thereby precluding the development and testing of models. 
Prescribed burning conditions are marginal by design wherein there seems to be a threshold between no fire spread and successful propagation. Others have reported thresholds in fire behavior as influenced by various fuel and environmental variables [68]. The factors that influence the thresholds are understood by successful prescribed fire managers in chaparral, but few systematic experiments have been conducted to describe these threshold conditions. We have recently completed a systematic experimental investigation of the important fuel and environmental variables that determine propagation success in laboratory-scale fires in common chaparral fuels $[9,10]$.

The present work focuses on the effect of terrain slope, one of the significant contributing factors that influence successful fire spread in chaparral. Slope effects were not studied in detail in our previous work. Prescribed fire operations adapt firing patterns in response to slope to control fire intensity and fire spread rate [1]. This is due to the fact that heat transfer processes during fire spread are sensitive to terrain slope. However the literature review reveals that only a limited number of experimental studies have investigated slope effects, especially for wildfire spread in marginal burning conditions. Hirano et al. [11] studied flame spread rate over thin paper at various inclined angles. It was observed the downward flame spread rate was almost constant in the range of $-90^{\circ}$ to $-30^{\circ}$ from the horizontal, and the upward flame was accelerative at angles of zero to $90^{\circ}$. The sharp increase in downward flame spread rate was also analyzed by experiments of Kashiwagi and Newman [12]. Drysdale and Macmillan [13] studied the rate of upward flame spread over inclined PMMA slabs. It was found that the flame spread rate was greatly enhanced at an inclination angle of $15-20^{\circ}$. Using pine needles as fuel, Dupuy [14], Van Wagner [15] and Viegas et al. [16] studied the effect of slope on laboratory fire spread. Weise and Biging [17], and Nelson [18] studied the interaction between wind and slope and its effect on the behavior of fire spread.

Over the last 40 years, a significant amount of interest in modeling forest fire spread has been generated within the scientific community. Rothermel [19] proposed a semiempirical model that could estimate fire spread rate under simplified conditions. The effect of slope on the rate of spread was expressed as $V=V_{0}\left(1+\phi_{s}\right)$, where $V_{0}$ is the spread rate under no wind and zero slope conditions, and $\phi_{s}$ is a slope factor. Other models incorporate heat transfer mechanisms, in particular, radiation heat transfer [2023]. The effect of slope is taken into consideration in computing the energy radiated by the flame in the direction of the unburned area. Albini [22] developed a model in which radiant heat transfer from the flame was considered the dominant mechanism of energy transfer to unburnt fuel ahead of the fire. Santoni and Balbi [23] developed a twodimensional non-stationary computational model for a fire spreading across a sloping fuel bed of Pinus pinaster litter. For an upslope fire, a supplementary radiant contribution was added to reflect the increased heat radiated from the flame to the unburned fuel.

When fire spreads upslope, it is observed that propagation depends not only on the increased radiant heat transfer rate but also on the complex aerodynamic convective heat transfer rate created by the interaction of the flame with an inclined surface [24]. Under certain situations as we observed, the convective heat transfer induced by this interaction became the dominant mechanism in determining fuel ignition and fire spread rate. In this paper, results of an experiment examining fire spread under marginal burning conditions are presented for upslope and downslope fires in various live chaparral fuel beds under differing environmental conditions. The results are analyzed to highlight the effect of slope on marginal burning. A statistical model is developed to estimate the probability of 
successful fire spread in chaparral fuels under different slope conditions. It is expected that the proposed model may provide guidelines for prescribed burning. Unsuccessful ignitions could be avoided if lower limits for ignition are known. The probability of spread success could be assessed to reduce costs associated with unsuccessful attempts when weather, topography and fuel parameters are known. On the other hand, current fire spread models $[3,19]$ lack lower limits on fire spread and assume that fires burn under all conditions. The study of marginal burning behavior would provide these limits as required.

\section{EXPERIMENTAL SETUP}

Chaparral is a mixture of several shrub species that grow in the Mediterranean climate of southern California. We collected chaparral vegetation from the North Mountain Experimental Area located about $50 \mathrm{~km}$ east of Riverside, California at an elevation of $1160 \mathrm{~m}$. Vegetation was collected in the morning and fuel samples prepared and burned on the same day at the Forest Fire Laboratory to minimize moisture loss during bagging, transportation, and fuel bed preparation. Foliage and branches with diameter $<0.64 \mathrm{~cm}$ from four chaparral species, manzanita (Arctostaphylos glandulosa), chamise (Adenostoma fasciculatum), hoaryleaf ceanothus (Ceanothus crassifolius), and scrub oak (Quercus berberidifolia), comprised the fuel.

The burn facility at the Forest Fire Laboratory is a $12.2 \mathrm{~m} \times 12.2 \mathrm{~m}$ metal building with a roof peak $11.1 \mathrm{~m}$ tall. The building is not environmentally controlled so temperature and relative humidity vary with ambient weather. Smoke is exhausted from the building via a roof vent and exhaust fans located atop the sloped roof. An experimental platform $(6.2 \mathrm{~m}$ long, $2.4 \mathrm{~m}$ wide and $0.6 \mathrm{~m}$ high) was constructed with steel frame and covered with brick. The chaparral fuel bed holder was placed on the platform (see Fig. 1). The fuel bed holder was constructed with an aluminum frame, $2.12 \mathrm{~m}$ long, $1.1 \mathrm{~m}$ wide, and $0.4 \mathrm{~m}$ high. The surface above the frame was covered by a piece of steel mesh with grid size $5 \times 10 \mathrm{~cm}$. A known mass of fuel for a single species was spread uniformly on the mesh, fluffed to remove tightly packed concentrations, and lightly and uniformly pressed down to the final fuel bed depth. Extraneous vertical strands above the bed surface were then clipped. Metal sheeting was placed on the lateral sides of the fuel bed holder to reduce flame front curvature caused by air entrainment from the lateral sides of the fuel bed along the fire spread direction. Because the foliage and branches in most chaparral shrubs are elevated above the ground with a vertical gap below (stem space), the fuel bed was elevated $0.4 \mathrm{~m}$ above the platform. Thus, air could be entrained from the bottom of the fuel bed into the fire. Fuels were ignited from one side in a $0.5 \mathrm{~m}$ section along the length of the fuel bed. Between $300 \sim 400 \mathrm{~g}$ of excelsior and a small amount of isopropyl alcohol were added uniformly in the ignition zone to initiate and sustain ignition. The natural changes in live fuel moisture content, environmental temperature and relative humidity were considered by collecting fuels and conducting experiments over the course of an annual cycle (2003 to 2004). An experiment was described as successful if the fuel ignited from the ignition zone and then propagated the length of the $2.0 \mathrm{~m}$ fuel bed. The experiment was unsuccessful if the fire did not propagate. All fire tests were video recorded by a digital video camcorder for post fire spread analysis.

The effect of slope was simulated by raising one side of the fuel bed. The slope angle is the angle, $\alpha$, between the fuel bed and the horizontal plane. Topographic slope is defined as the ratio between vertical rise and horizontal distance expressed as a percentage: 
slope $=100 \tan (\alpha)$. Positive slope indicates uphill fire spread; negative slope indicates downhill fire spread.

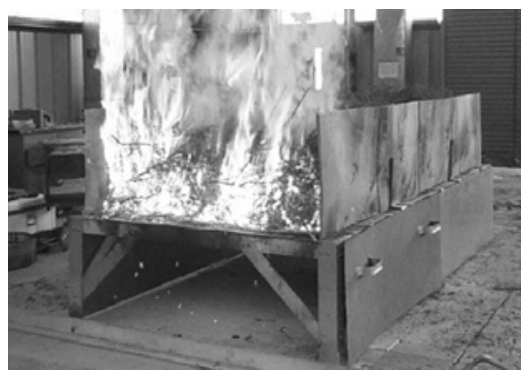

Fig. 1. Fuel bed constructed of live foliage and branches of chamise with $2.0 \mathrm{~m}$ long, $1.0 \mathrm{~m}$ wide and $0.4 \mathrm{~m}$ depth. The fire illustrates the initial ignition.

\section{RESULTS AND DISCUSSIONS}

\section{Effect of Slope Setup}

As seen in Fig. 1, the chaparral fuel bed was placed on a large platform. This platform was initially designed to tilt up to an angle of $45^{\circ}(100 \%)$ to the horizontal, and the chaparral fuel could be ignited from downside (upside) to model the effect of upslope (downslope) fire. This configuration is designated setup A as shown in Fig 2a. Because of safety concerns involving use of the large tilting platform, a smaller tilting fuel bed was designed (B). Setup B was designed to lift one side of the fuel bed to different angles (see Fig. 2b) while keeping the heavy platform horizontal. Setup B is significantly easier to arrange and led to unexpected, yet insightful experimental results. Based on our experimental observation, setup B was modified suitably to model setup A in the following manner. The fuel bed was redesigned by attaching a piece of steel plate to the bottom of the fuel bed with a $0.4 \mathrm{~m}$ gap. The steel plate can be tilted with the fuel bed, and the entrainment of ambient air to the region underneath the fuel bed is thus blocked. To reduce heat reflection, the steel plate was covered with heat insulation board. The redesigned slope setup was named as C (Fig. 2c).

Using slope setup B, a series of experiments was completed for three slope levels: zero slope, $40 \%$ upslope $\left(\alpha=21.8^{\circ}\right)$, and $60 \%$ upslope $\left(\alpha=31^{\circ}\right)$. Other experimental conditions were essentially unchanged. The fuel was chamise with measured average moisture content (dry-fuel basis) $56 \%$, fuel bed depth was $0.4 \mathrm{~m}$ with fuel loading $5.5 \mathrm{~kg} / \mathrm{m}^{2}$, no wind, ambient temperature was $31.5^{\circ} \mathrm{C}$ and relative humidity was $37 \%$. Each case was repeated two times and the experimental sequence was random. All fire tests were video recorded.

For zero slope setup, Fig. 3 illustrates the time evolution of fire spread by presenting three fire images captured from the videotape at different times. Fire was ignited at the left end of the fuel bed $(x=0 \sim 0.5 \mathrm{~m})$, and propagated to the right. The length scale $(0.5 \mathrm{~m})$ painted on the metal sheet is used to show the position of the fire front. Fig. 3a shows the fire behavior at time $t=60 \mathrm{~s}$ after the initial ignition. The fire is strong and the flame height is about $1.7 \mathrm{~m}$. In this paper, the flame height was measured from the bottom of the fuel bed. Figure $3 \mathrm{~b}$ shows the fire front has spread to the center position $(x \approx 1 \mathrm{~m})$ of the fuel bed at time $t=178 \mathrm{~s}$. It is seen that fire is weak and the flame height is about 
$0.65 \mathrm{~m}$. After the initial ignition, the fuel burning rate and fire spread rate reached a steady state at this time. Figure $3 \mathrm{c}$ shows the fire burned to the right end side $(x \approx 2 \mathrm{~m})$ of the fuel bed at time $t=597 \mathrm{~s}$. Because of the collimation error, the observed fire front position from the videotape should be revised. For steady-state fire spread, the fire behavior shown in Fig. 3c was similar to that in Fig. 3b. From these two images we can approximate the fire spread rate to be $0.143 \mathrm{~m} / \mathrm{min}$, or $0.0024 \mathrm{~m} / \mathrm{s}$. For marginal burning analysis, this fire test was described as successful when the live chaparral fuel ignited from the burning zone and then propagated the length of the fuel bed. In a second repetition test with zero slope, the fire spread was successful and the approximated spread rate was $0.171 \mathrm{~m} / \mathrm{min}$.
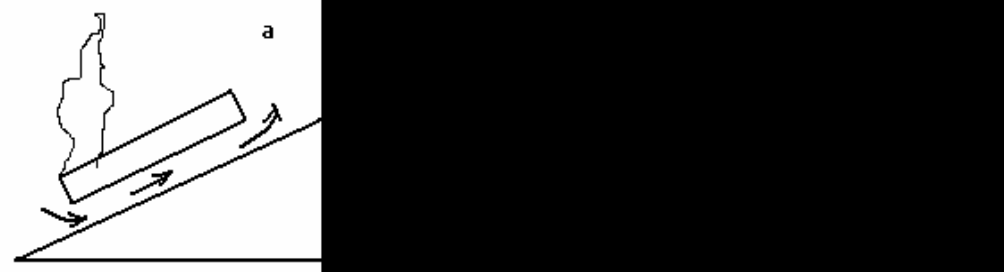

Fig. 2. Illustration of fuel bed slope setup A, B and C.

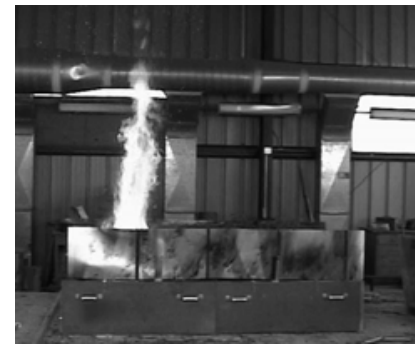

(a)

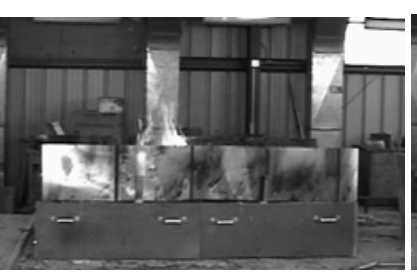

(b)

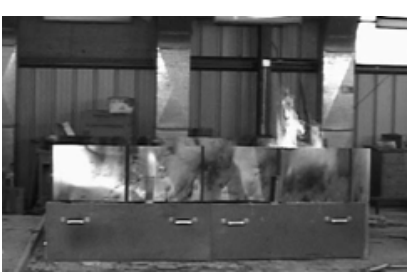

(c)

Fig. 3. Images of fire captured from videotape at time (a) $t=60 \mathrm{~s}$, (b) $t=178 \mathrm{~s}$, and (c) $t=597 \mathrm{~s}$, after the initial ignition with zero slope.

For other upslope fire spread cases with slope $40 \%$ and $60 \%$, it was anticipated that fire would spread successfully and with faster spread rate in comparison with the zero slope case. However, the completed experiments showed a surprisingly contrary result that the fire didn't spread. For upslope 60\%, Fig. 4 illustrates the time evolution of the fire spread. Fire was ignited at the lower end of the fuel bed and then propagated upward. At time $t=11 \mathrm{~s}$ after initial ignition, Fig. $4 \mathrm{a}$ shows that the flame plume was well-developed with a flame height of about $1.6 \mathrm{~m}$. At time $t=87 \mathrm{~s}$, flame height was reduced to $1.2 \mathrm{~m}$ (Fig. 4b). At time to $t=133 \mathrm{~s}$, the fire plume was weakening and finally extinguished (Fig. 4c). The fire failed to spread at upslope $60 \%$ for setup B. In repeated tests for slopes of $40 \%$ and $60 \%$, all fires were observed to fail to spread for setup B. 


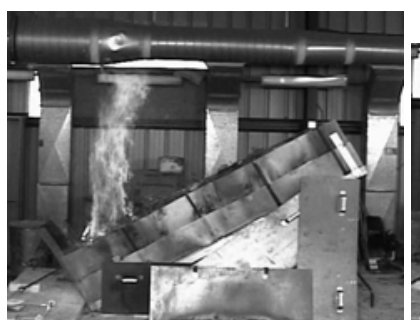

(a)

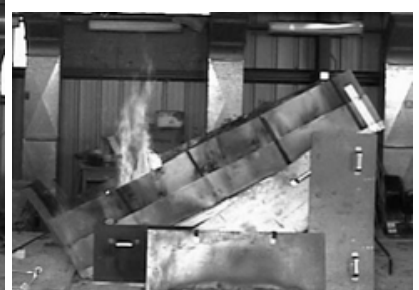

(b)

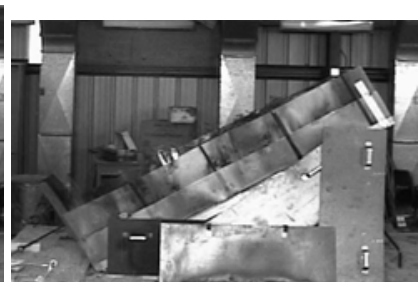

(c)

Fig. 4. Images of fire captured from videotape at time (a) $t=11 \mathrm{~s}$, (b) $t=87 \mathrm{~s}$, and (c) $t=133 \mathrm{~s}$, after the initial ignition with $60 \%$ slope and setup B.

As analyzed by many researchers [20-23], upslope fires are closer to the unburned fuel, thereby increasing the radiation heat transfer rate incident on the fuel, the preheating rate, and thus the rate of spread. For setup B, Fig. 4 shows these factors still affect the burning of chaparral fuel by increasing the radiative heat transfer to the fuel ahead of the flame front. However, setup B did not promote vigorous fire spread. In our limited marginal burning tests using setup $A$, it was found that the upslope conditions enhanced fire spread. By comparing the designs of setup A and B, we speculate that the main difference was the aerodynamic effect created by the inclined platform. Due to buoyancy, the fire plume over the burning zone induces a vertical upward movement, and the ambient air is entrained into the fire plume. For setup B (Fig. 2b), air is entrained from both the left and right sides by passing through the bottom of the fuel bed before entering the fire plume. In this case the air entrainment from both sides is almost balanced, and the fire plume is vertical (Fig. 4). For the setup A (Fig. 2a), however, the air entrainment into the fire plume from the right side is confined by the platform. The air entrainment from both sides is not balanced. On the inclined platform, a local wind to blow up-slope is formed because of the unbalanced air entrainment and the draft of the fire plume. This local wind aids in the convective heating of the unburnt fuel ahead of the flame front. The steeper the slope, the more rapidly the fire will burn up-slope (and more intensely) because of both enhanced convective and radiative heat transfer rates.

This proposed phenomenological model was verified by our experimental observation in the limited marginal burning tests using slope setup A. For upslope 70\%, Fig. 5 illustrates a fire image captured from the videotape. After the initial ignition, the fire spreads up the slope. Because of the local wind created by the surface confinement and air entrainment into the fire, Fig. 5 shows that the flame is tilted toward the fuel bed. This is sometimes referred to as "flame attachment." In our experiments, the local wind was observed by tracing the smoke flow that moved upward along the inclined platform. At the right (upper) end of the fuel bed, Fig. 5 shows that many tiny fire brands were blown out by the local wind. This analysis is also supported by the experiments conducted by Wu et al. [24] to study the interaction of fire plume with inclined surface. It was concluded that the rapid fire spread rate observed at a critical inclination angle [13] is attributable to a sharp increase in the convective heat transfer rate. 


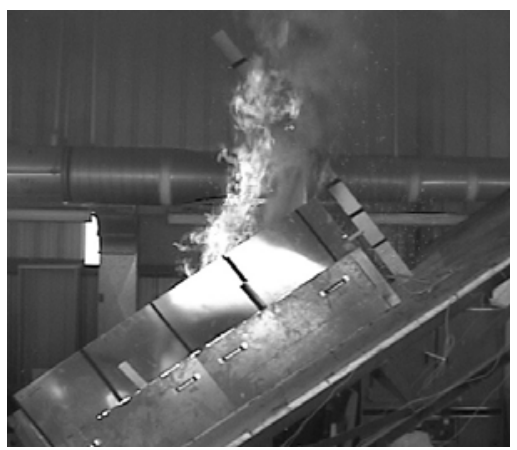

Fig. 5. Illustration of a fire image with the slope setup A of 70\%.

The role of convection induced by the fire, eventually enhanced by terrain slope, was emphasized by Viegas and Pita [25] in analyzing fire spread in canyons. They showed that the fire has a dynamic behavior and its properties depended not only on the canyon geometry but also on the history of fire development. The convection induced by the fire was enhanced by terrain curvature, and the fire accelerated causing the well-known blowup that is associated with canyon fires. The rate of spread of the head fire increased continuously even in the absence of wind or any other special features that are sometimes invoked to justify such fire behavior.

The contrary results obtained from setups A and B demonstrated that the aerodynamic effect created by the interaction between the flame and the inclined solid surface becomes the dominant mechanism in determining burning success and the subsequent fire spread rate. Having obtained a better understanding of the competing effects of radiative and convective heat transfer rates, setup C (Fig. 2c) was designed by modify setup B suitably. For upslope 40\%, Fig. 6 shows the time evolution of fire spread in the redesigned fuel bed. The experimental condition was close to the case shown in Fig. 4, but was not the exactly same because of the natural change of live chaparral fuel and the uncontrolled ambient environment. The fuel conditions were chamise with moisture content $59 \%$, fuel bed depth $=0.4 \mathrm{~m}$, and fuel loading $=5.07 \mathrm{~kg} / \mathrm{m}^{2}$; environmental conditions were no wind, ambient temperature $\left(T_{a}\right)=21.7^{\circ} \mathrm{C}$ and relative humidity $(R H)=50 \%$. Fire spread successfully (Fig. 6a-c). The fire plume was well established and the flame height was sustained over the length of the fuel bed. The approximated fire spread rate was $0.56 \mathrm{~m} / \mathrm{min}$. Compared with the case shown in Fig. 4, this result was reasonable and consistent with the above phenomenological model of the effect of slope.

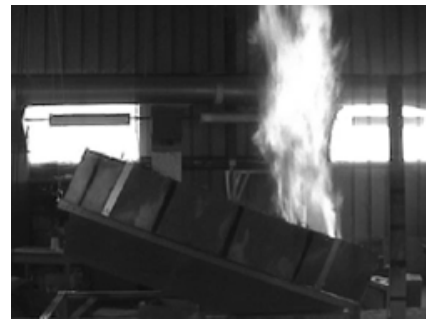

(a)

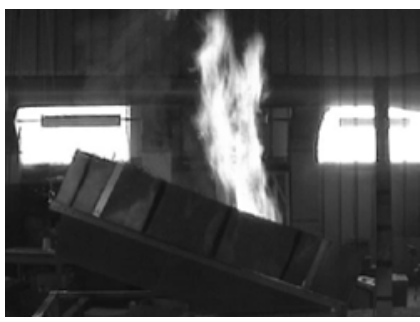

(b)

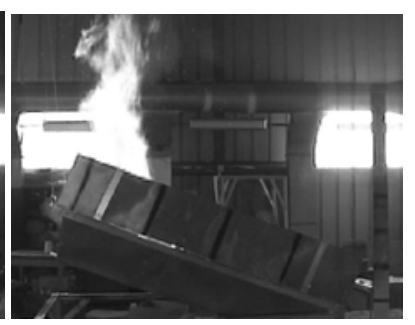

(c)

Fig. 6. Images of fire captured from videotape at time (a) $t=19 \mathrm{~s}$, (b) $t=68 \mathrm{~s}$ and (c) $t=176 \mathrm{~s}$, after the initial ignition with the redesigned slope setup $\mathrm{C}$ of $40 \%$. 


\section{Effect of Slope on Marginal Burning}

A series of fire spread experiments was conducted to study the effect of slope on marginal burning of live chaparral fuel by using setup C. By spanning fuel burning conditions from downslope to upslope (-70\% to $70 \%)$, we obtained the critical marginal slope percent that delineated successful fire spread from unsuccessful cases. All experiments were conducted under no wind conditions. Two fuel bed depths $(20 \mathrm{~cm}$ and $40 \mathrm{~cm}$ ) were used to change the fuel loading. Fuel moisture content of samples burned on the day of collection ranged from $49 \%$ for chamise to $106 \%$ for manzanita. Chamise fuel moisture was $91 \%$ on $5 / 9 / 2003,53 \%$ on $9 / 11 / 2003,61 \%$ on $11 / 17 / 2003,60 \%$ on 4/7/2004, and 49\% on 9/7/2004. Manzanita, ceanothus and scrub oak exhibited changes in fuel moisture content similar to chamise. Ambient conditions in January were $T_{a}=$ $18^{\circ} \mathrm{C}, R H=70 \%$; conditions in August were $T_{a}=39^{\circ} \mathrm{C}, R H=20 \%$.

In the experiments, the slope percent was a static value that could be controlled accurately. The experimental uncertainties come from the heterogeneous nature of the fuel samples and fuel bed, ambient temperature and relative humidity. Uncertainty would be reduced by averaging across repetitions for the same nominal values of all variables. Seventy-three (or $42 \%$ ) of 173 tests resulted in successful fire spread for different slope percent, fuel moisture content, fuel loading and ambient conditions. To quantify marginal burning, we define a "Marginal Burning Index" (MBI) that is indicative of a fire's proximity to a successful spread. By excluding the ignition zone, MBI was calculated as the area fraction of fuel burned in the fuel bed after the initial ignition. A successful fire spread had MBI $=1.0$, and fires that went out had MBI value in a range of $0<\mathrm{MBI}<1$. Near the marginal slope percent, the MBI value was observed to be close to 1.0.

Figure 7a illustrates the MBI values obtained from upslope fire spread experiments in different slope range. There were four shrub fuels with mean moisture content: chamise $(M=58 \%)$, ceanothus $(M=88 \%)$, manzanita $(M=82 \%)$, and scrub oak $(M=69 \%)$. The fuel bed depth was $0.2 \mathrm{~m}$. Other experimental conditions were similar. It is found that all MBI values increased with upslope percent. For chamise, the marginal slope percent was approximated as $40 \%$; a fire would spread successfully above this slope. Over a narrow range between $30 \% \sim 40 \%$, there was a sharp increase in MBI values from 0.25 to 1 . This observation corresponds to other researchers' results $[13,24]$ that there is a critical inclination angle for the change of fire behavior and fire spread rate. As analyzed above for upslope fire spread, with an increase in slope percent to a critical point, there would be a great increase in convective heat transfer rate that leads to a successful fire spread. It's well known that high moisture content can hinder the burning of cellulosic fuels. Fig. 7 a shows that the marginal slope percent increases with moisture content as $55 \%$ for manzanita, $60 \%$ for ceanothus and scrub oak. This means that the marginal slope percent varies widely with fuel type and fuel moisture content. 


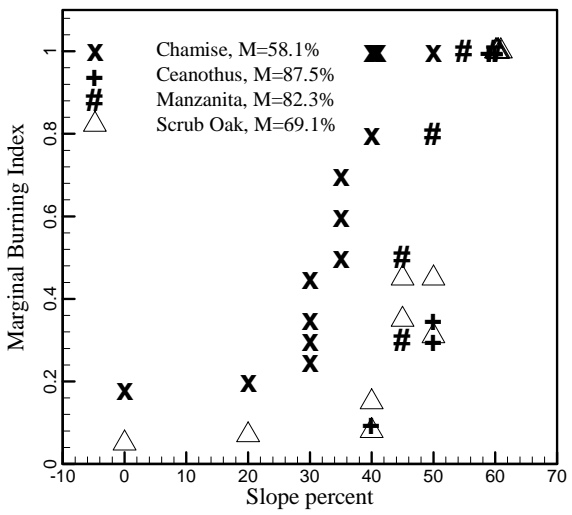

(a)

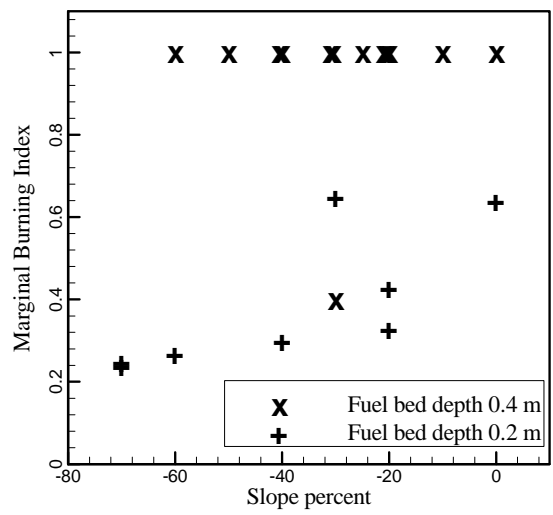

(b)

Fig. 7. Marginal burning index obtained from marginal burning experiments for various fuel conditions and (a) upslope; (b) downslope.

For downslope fire spread, the effect of slope on marginal burning was not as sensitive as in the case of upslope fire. Figure $7 \mathrm{~b}$ illustrates the MBI values obtained from downslope fire spread experiments for slopes from 0 to $-70 \%$. The fuel was chamise with moisture content $57 \%$. The fuel bed depth was 0.2 and $0.4 \mathrm{~m}$, respectively, implying a doubling of fuel loading. For fuel bed depth $0.4 \mathrm{~m}$, Fig. $7 \mathrm{~b}$ shows that almost all fire spread cases were successful and only one was not. For fuel bed depth $=0.2 \mathrm{~m}$, all fires went out. The MBI value decreased with slope from 0 to $-70 \%$ but the change was smoother than the upslope case. We observed that fuel bed depth changed the marginal burning status. Larger fuel bed depth increased probability of fire spread success. Another important factor to affect the marginal burning is the ambient wind that was discussed in our previous work $[9,10]$.

Based on 173 marginal burning tests for no wind and different slope percent, fuel moisture content, fuel loading and ambient conditions, a statistical model was developed to estimate the probability of fire spread success. It is expected to provide guidelines for prescribed burning success. Because the response variable (spread success) was binary, a stepwise logistic regression method [26] was used. The model was developed as

$X=-0.34+0.05 S I+1.89 L+0.12 T_{a}-0.11 M$

$\operatorname{Pr}($ success $=Y)=e^{X} /\left(1+e^{X}\right)$

The probability $\mathrm{Pr}$ of fire spread success was set equal to the function of parameters $\mathrm{Sl}$ (slope percent, \%), $L$ (dry fuel loading, $\mathrm{kg} / \mathrm{m}^{2}$ ), $T_{a}$ (ambient temperature, ${ }^{\circ} \mathrm{C}$ ) and $M$ (live fuel moisture content, \%). The fitted model correctly classified nearly $86 \%$ of the 173 fires in the data. This equation is different from our earlier, published equations $[9,10]$. The coefficients differ because a different subset of the entire data set was used for estimation. When the data set is better balanced with regard to equal replication of the experimental variables, a logistic model will be developed from the entire data set. 


\section{Effect of Slope on Fire Spread Rate}

The slope of the fuel bed influenced not only the ignition of the chaparral fuel but also the fire spread rate. Fire spread rate is an important variable in wildfires since it is indicative of the potential fire intensity and fire danger. For successful fire spread tests, Fig. 8 illustrates fire spread rate in chaparral fuel beds as a function of slope percent from $-60 \%$ to $70 \%$. Fuel moisture content, fuel loading, and ambient conditions vary between data points. Figure 8 shows that the effect of slope from $-70 \%$ to $30 \%$ on fire spread rate is relatively minor. With slope above $40 \%$, the fire spread rate increases greatly. This result is consistent with our analysis of Fig. 7a on the effect of slope on MBI, and agree with the results obtained by other researchers $[13,17,24]$.

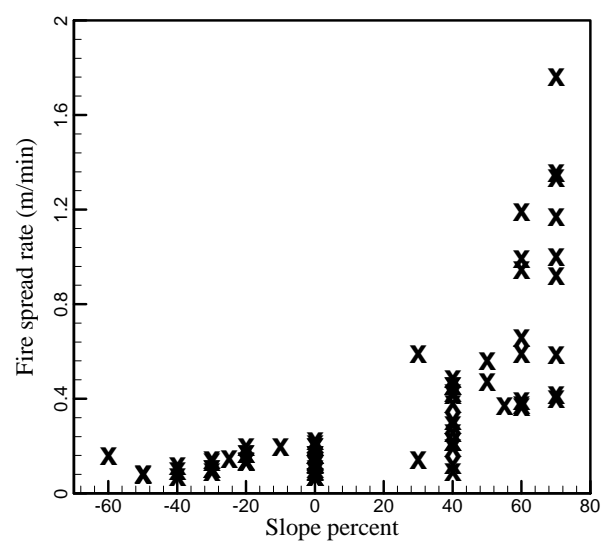

Fig. 8. Fire spread rate of live chaparral fuel plotted as the function of the slope percent.

\section{CONCLUSION}

Current fire spread models do not adequately model the transition between no spread and spread in live chaparral fuels, especially when the effects of terrain slope is included. We have conducted 173 experiments to study the effect of slope on fire spread success for 4 different species of chaparral in the laboratory. In examining two fuel bed slope setups, it was found the upslope fire spread depends not only on the increased radiant heat transfer rate but also on the aerodynamic effect created by the interaction of the flame with the inclined surface. Under our experimental conditions, the convective heat transfer induced by this interaction becomes the dominant mechanism in determining fire spread success. Experimental results demonstrate that there exists a critical marginal slope below which fire spread is unsuccessful, and above which it is successful. This critical marginal slope varies widely with fuel type, moisture content, and fuel loading. The direction of fire spread relative to slope (up or down) has different effects on marginal burning behavior of live chaparral fuels. Using a stepwise logistic regression method to analyze these 173 fires, a logistic model was developed to predict the probability of fire spread success. It is clear that the combined effects of wind and slope are not adequately modeled, and more experimental work is still needed for direct application in a prescribed fire. 


\section{ACKNOWLEDGEMENTS}

The funding source for this research is the USDA/USDI National Fire Plan administered through a Research Joint Venture Agreement No. 01-JV-11272166-135 with the Forest Fire Laboratory, Pacific Southwest Research Station, Riverside, CA. We appreciate the efforts of Joey Chong, David Kisor, Lulu Sun, Watcharapong Tachajapong, Luis Cardenas, Michael Sheppy, and Anurag Sridharan in collecting the fuels, building the

fuel beds, and assisting with the experimental burns.

\section{REFERENCES}

[1] Green, L.R., "Burning by Prescription in Chaparral," USDA Forest Service, Gen. Tech. Rep. PSW-51, 1981, 1-36 p.

[2] Raybould, S., and Roberts, T., "A Matrix Approach to Fire Prescription Writing," Fire Management Note, 44, (4), pp. 7-10, (1983).

[3] Andrews, P.L., "BEHAVE Fire Behavior Prediction and Fuel Modeling System," USDA Forest Service, Gen. Tech. Rep. INT-194, Ogden, UT, 1986, $130 \mathrm{p}$.

[4] Cohen, J.D., "Estimating Fire Behavior with Forecast: User's Manual," Gen. Tech. Report PSW-90, 1986, May, 1-11 p.

[5] Campbell, D., "The Campbell Prediction System," Wildland Fire Specialists, Ojai, CA, 1995, 129 p.

[6] Bruner, A.D., and Klebenow, D.A., "Predicting Success of Prescribed Fires in Pinyon-juniper Woodland in Nevada," USDA Forest Service, Res. Paper INT219, Ogden, UT, 1979, 11 p.

[7] McCaw, W.L., Predicting Fire Spread in Western Australian Mallee-heath Shrubland, Ph.D. dissertation, University of New South Wales, Canberra, Australia, 1997.

[8] Wilson, R.A. Jr., "Observations of Extinction and Marginal Burning States in Free Burning Porous Fuel Beds," Combustion Science and Technology, 44, pp. 179-194, (1985).

[9] Zhou, X., Weise, D., and Mahalingam, S., "Experimental Measurements and Numerical Modeling of Marginal Burning in Live Chaparral Shrub Fuel Beds," Proc. Combust. Inst., 30, 2005, pp. 2287-2294.

[10] Weise, D., Zhou, X., Sun, L., and Mahalingam, S., "Fire Spread in Chaparral 'Go or No-go?'," Int. J. Wildland Fire, 14, pp. 99-106, (2005).

[11] Hirano, T., Noreikis, S.E., and Waterman, T.E., "Postulations of Flame Spread Mechanisms," Combustion and Flame, 22, pp. 353-363, (1974).

[12] Kashiwagi, T., and Newman, D.L., "Flame Spread Over an Inclined Thin Fuel Surface," Combustion and Flame, 26, pp. 163-177, (1976).

[13] Drysdale, D.D., and Macmillan, A.J.R., "Flame Spread on Inclined Surfaces," Fire Safety J., 18, pp. 245-254, (1992). 
[14] Dupuy, J.L., "Slope and Fuel Load Effects on Fire Behavior: Laboratory Experiments in Pine Needles Fuel Beds," Int. J. Wildland Fire, 5,(3), pp. 153164, (1995).

[15] Van Wagner, C. E., "Effect of Slope on Fires Spreading Downhill," Can. J. For. Res. 18, pp. 818-820, (1988).

[16] Viegas, D.X., "Slope and Wind Effects on Fire Propagation," Int. J. Wildland Fire, 13, (2), pp. 143 - 156, (2004).

[17] Weise, D.R. and Biging, G.S., "Effects of wind velocity and slope on fire behavior," in Proceedings of the Fourth International Symposium on Fire Safety Science, 1994, Ottawa, pp. 1041-1051.

[18] Nelson, R.M., Jr., "An effective wind speed for models of fire spread," Int. J. Wildland Fire 11: 153-161 (2002).

[19] Rothermel, R.C., "A Mathematical Model for Predicting Fire Spread in Wildland Fuels," USDA Forest Service, Res. Paper INT-115, Ogden, UT, 1972.

[20] Pagni, P.J., and Peterson, T.G., "Flame Spread Through Porous Fuels," Proc. Combust. Inst., 14, pp. 1099-1107, (1973).

[21] Albini, F.A., "A Physical Model for Fire spread in Brush," Proc. Combust. Inst., 11, pp. 553-560, (1967).

[22] Albini, F.A., "Wildland Fire Spread by Radiation - A Model Including Fuel Cooling by Natural Convection," Combust. Sci. and Tech., 45, pp. 101, (1986).

[23] Santoni, P.A., and Balbi, J.H., "Modelling of Two-dimensional Flame Spread Across a Sloping Fuel Bed," Fire Safety J., 31, pp. 201-225, (1998).

[24] Wu, Y., Xing, H.J. and Atkinson, G., "Interaction of Fire Plume with Inclined Surface," Fire Safety J., 35, pp. 391-403, (2000).

[25] Viegas, D.X., and Pita, L.P., "Fire Spread in Canyons," Int. J. Wildland Fire, 13, pp. 253-274, (2004).

[26] Hosmer, D.W., and Lemeshow, S., Applied logistic regression, $2^{\text {nd }}$ ed., Wiley, New York, 2000. 